\title{
HETEROGENEITY IN TOURISM MOTIVATIONS: THE CASE OF THE ALGARVE
}

\author{
Jaime Serra, Antónia Correia and \\ Paulo M. M. Rodrigues
}

\begin{abstract}
This chapter examines how motivational and behavioral indicators influence overnight stays of international tourists in the Algarve. The method includes a first selection of the motivations associating with high heterogeneity over the years considered, followed by a correlation matrix to assess how tourists' behavioral patterns relate with overnight stays. Behavioral patterns by year are defined based on motivations, socio-demographics, intentions, and lagged satisfaction. The correlation analysis was conducted using 15,542 observations collected at Faro international airport, from 2007 to 2010. The findings include 10 main motivations and reveal that these motivations are statistically different by country and over the years. This study contributes to the overall understanding of the dynamics of tourism demand.
\end{abstract}

Keywords: Algarve; demand; motivation; tourism; socio-demographics

\footnotetext{
Tourists' Behaviors and Evaluations

Advances in Culture, Tourism and Hospitality Research, Volume 9, 85-95

Copyright (C) 2014 by Emerald Group Publishing Limited

All rights of reproduction in any form reserved

ISSN: 1871-3173/doi:10.1108/S1871-317320140000009010
} 